\title{
EFFECT OF AN ADDITIONAL HYDROPHILIC VERSUS HYDROPHOBIC COAT ON THE QUALITY OF DENTINAL SEALING PROVIDED BY TWO-STEP ETCH-AND-RINSE ADHESIVES
}

\author{
Safira Marques de Andrade e SILVA ${ }^{1}$, Marcela Rocha de Oliveira CARRILHO ${ }^{2}$, Luiz MARQUEZINI JUNIOR ${ }^{3}$, \\ Fernanda Cristina Pimentel GARCIA ${ }^{4}$, Adriana Pigozzo MANSO ${ }^{5}$, Marcelo Corrêa ALVES ${ }^{6}$, Ricardo Marins de CARVALHO ${ }^{7}$
}

\author{
1- DDS, MS,PhD , Department of Restorative Dentistry and Dental Materials, Dental School of Piracicaba, University of Campinas, Piracicaba, SP, \\ Brazil. \\ 2- DDS, PhD, Clinical Assistant Professor, Department of Operative Dentistry, University of Florida, College of Dentistry, Gainesville, FL, USA . \\ 3- DDS, Ms, PhD, Assistant Professor, Department of Operative Dentistry, University of Várzea Grande, Dental School, Várzea Grande, SP, Brazil. \\ 4- DDS, Ms, PhD,Assistant Professor, Department of Operative Dentistry, University of Brasília, Dental School, Brasília, DF, Brazil. \\ 5- DDS, Ms, PhD student. Department of Dental Materials, University of São Paulo, Dental School, São Paulo, SP, Brazil and Department of Research \\ and Development, Bisco Inc., Schaumburg, IL, USA. \\ 6- Ms,Information Technology Specialist, PhD student. Department of Morphology and Anatomy, and Dental Materials, Dental School of Piracicaba, \\ University of Campinas, Piracicaba, SP, Brazil. \\ 7- DDS, PhD, Associate Professor, Department of Operative Dentistry, University of Florida, College of Dentistry, Gainesville, FL, USA . \\ Corresponding address: Dr. Marcela Carrilho. Address: Rua Alagoas, 475 ap. 13B - Higienopólis, São Paulo-Brazil - 01242-001- Phone: 55-11-3668- \\ 6779 -e-mail: marcelacarrilho@gmail.com
}

Received: May 13, 2008 - Modification: August 31, 2008 - Accepted: September 22, 2008

\begin{abstract}
$O$

bjective: To test the hypothesis that the quality of the dentinal sealing provided by two-step etch-and-rinse adhesives cannot be altered by the addition of an extra layer of the respective adhesive or the application of a more hydrophobic, non-solvated resin. Material and Methods: full-crown preparations were acid-etched with phosphoric acid for $15 \mathrm{~s}$ and bonded with Adper Single Bond (3M ESPE), Excite DSC (Ivoclar/Vivadent) or Prime \& Bond NT (Dentsply). The adhesives were used according to the manufacturers' instructions (control groups) or after application to dentin they were a) covered with an extra coat of each respective system or b) coated with a non-solvated bonding agent (Adper Scotchbond Multi-Purpose Adhesive, 3M ESPE). Fluid flow rate was measured before and after dentin surfaces were acid-etched and bonded with adhesives. Results: None of the adhesives or experimental treatments was capable to block completely the fluid transudation across the treated dentin. Application of an extra coat of the adhesive did not reduce the fluid flow rate of adhesive-bonded dentin ( $p>0.05)$. Conversely, the application of a more hydrophobic non-solvated resin resulted in significant reductions in the fluid flow rate $(p<0.05)$ for all tested adhesives. Conclusions: The quality of the dentinal sealing provided by etch-and-rinse adhesives can be significantly improved by the application of a more hydrophobic, non-solvated bonding agent.
\end{abstract}

Key words: Adhesives permeability. Dentinal sealing. Hydrophobic coating.

\section{INTRODUCTION}

In adhesive dentistry the concept of clinical progress has been often earmarked by procedural simplification. Classical multi-step adhesives have been, increasingly, replaced by simplified "single-step" systems that are, apparently, simpler and faster to use. Simplification of contemporary dental adhesives has occurred, however, at the expenses of an increasing incorporation of hydrophilic monomers (i.e. HEMA, BPDM, MDP, Phenyl-P). Not coincidentally, these contemporary hydrophilic adhesives have shown to draw water from hydrated dentin through an apparently intact, polymerized adhesive layer ${ }^{7,11,24}$. If the dentinal fluid passes through the adhesive, it may accumulate on its own surface, thereby interfering with coupling to the resin composites ${ }^{4,27}$. Thus, instead of creating a perfect sealing of dentin, polymerized hydrophilic adhesives actually behave as permeable membranes that potentially

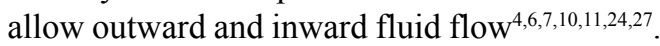

Deficient sealing of dentin may be analysed from several perspectives. One can argue that placing adhesive comonomer mixtures in an inhospitable environment such as the water-wet acid-etched dentin will inexorably result in the formation of porous polymers that are prone to absorb water ${ }^{9,15}$. Conversely, the use of more hydrophobic, less permeable resins such as the dentin bonding adhesives may 
supposedly prevent this problem and further improve the durability of resin-dentin bonds, because these materials tend to exhibit much lower ability to absorb water ${ }^{15}$. However, the use of hydrophobic monomers as bonding agents to dentin is not effective yet as they are not miscible to acidetched dentin that is intentionally saturated with water ${ }^{3,20}$.

While the water-wet bonding technique ${ }^{13}$ is not modified to permit hydrophobic adhesives to be coaxed into acidetched dentin, the intrinsic permeability of two-step etchand-rinse adhesives ${ }^{24,25}$ should be minimized, which is thought to be important in prolonging the integrity of the resultant resin-dentin bonds. Studies have demonstrated that three-step etch-and-rinse adhesives and two-step self-etching systems, which deliberately indicate the application of multiple coats of their primer solution and/or a coat of a more hydrophobic resin over the hybridized dentin, seem to constitute overlying adhesive layers and hybrid layers that are naturally less permeable than those formed when using the most simplified, "single-step" systems ${ }^{5,6,7}$. Thus, the objective of this study was to evaluate whether the ability of two-step etch-and-rinse adhesives to seal dentin may be changed when these systems are covered with an extra coat of the same two-step etch-and-rinse system or a coat of a more hydrophobic non-solvated bonding agent. The null hypotheses tested were that the quality of the dentinal sealing provided by two-step etch-and-rinse adhesives cannot be altered by the application of: 1) an extra coat of the respective two-step etch-and-rinse system or 2) a coat of a more hydrophobic, non-solvated bonding agent.

\section{MATERIAL AND METHODS}

\section{Teeth Preparation}

Fifty-four non-carious human third molars extracted for orthodontics reasons were collected after the patients' informed consent had been obtained under a protocol reviewed and approved by the Human Research Ethics Committee of the Bauru School of Dentistry, University of São Paulo. These teeth were stored in saline containing 1\% thymol at $4{ }^{\circ} \mathrm{C}$ and used within no longer than 6 months after extraction.

Crown preparations with chamfer margins located on the cementum/enamel junction (CEJ) were performed in the extracted teeth with diamond burs under copious air-spray (4137 KG Sorensen, Barueri, SP, Brazil). From prepared teeth, crown-segments were further obtained by transversally sectioning the teeth roots at $2 \mathrm{~mm}$ below the CEJ using a slow-speed diamond saw (IMPTECH PC 10, Boksburg, Republic of South Africa), under water cooling. The pulp tissue was carefully removed with a pair of small forceps. Care was taken to avoid touching the pulp chamber walls for consequently not crushing the predentine toward the dentinal tubules, which could alter the final permeability of dentin (Dr. David Pashley, personal communication). The resulting crown-segments were glued to Plexiglass slabs using a viscous cyanoacrylate (Zapit, Dental Ventures of American, Corona, CA, USA), which also covered the entire peripheral cementum. Each Plexiglass slab was penetrated by a short length of 18-gauge stainless steel tubing, which ended flush with the top of the Plexiglass slab. This tube permitted the pulp chamber to be filled with water and to be connected to an automated flow-recording device (Flodec System, De Marco Engineering, Geneva, Switzerland) (Figure 1).

\section{Bonding Procedures}

Three two-step etch-and-rinse adhesives were evaluated in this study: Adper Single Bond (SB - 3M ESPE, St. Paul, MN, USA), Excite DSC (EX - Ivoclar/Vivadent, Schaan, Liechtenstein) and Prime \& Bond NT (PB - Dentsply

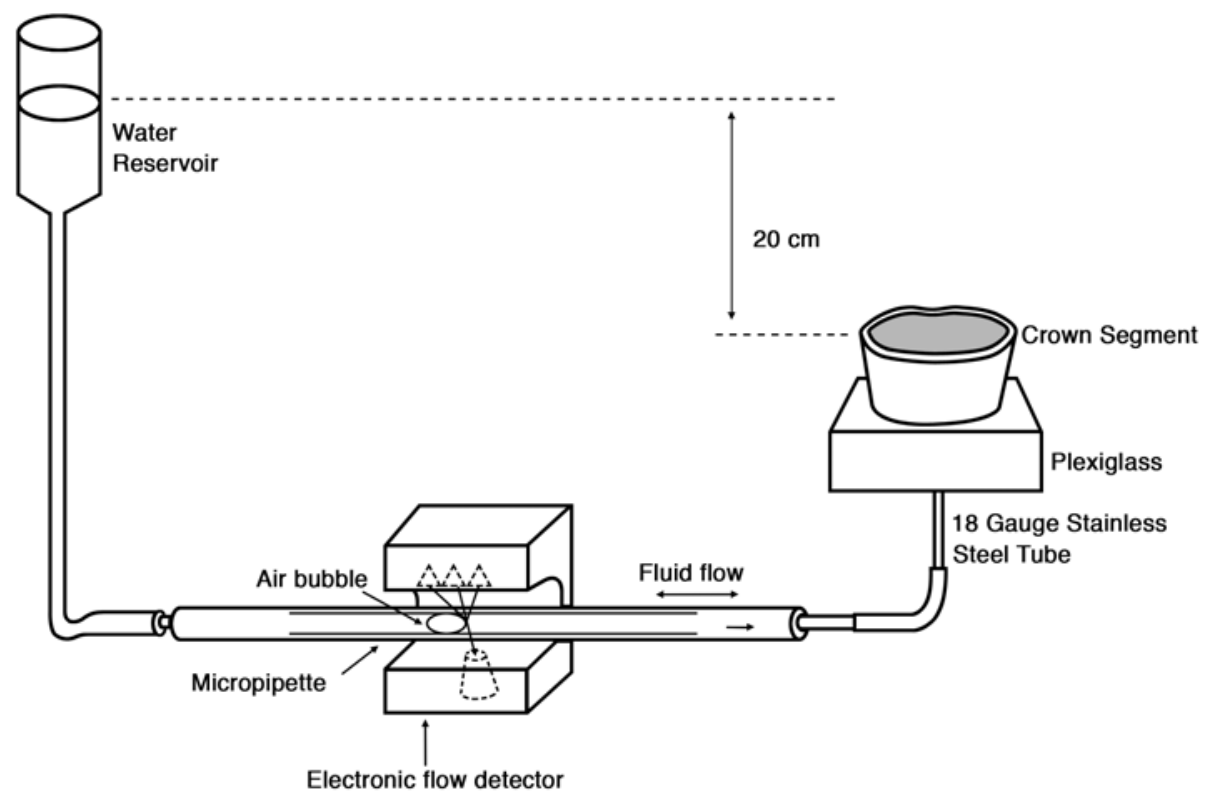

FIGURE 1- Schematic presentation of the fluid-filtration apparatus used to perform repeated measurements of the permeability of dentin surfaces after acid-etching and after resin-bonding 
DeTrey, Konstanz, Germany) (Table 1).

The crown-segments were randomly divided into nine groups of six specimens each $(n=6)$, corresponding to the three adhesives applied in three different conditions: 1) according to the manufacturers' instructions (controls); 2) with an additional coat of the respective adhesive and 3) with a coat of a more hydrophobic non-solvated resin bonding agent (Adper Scotchbond Multi-Purpose Adhesive, 3M ESPE).

During the bonding procedures, the hydrostatic pressure in the pulp chamber was null $\left(0 \mathrm{~cm} \mathrm{H}_{2} \mathrm{O}\right)$ in order to avoid excessive fluid contamination of the bonding area ${ }^{10}$. The extra coat of the respective two-step etch-and-rinse adhesive (i.e. SB, EX or PB) or the more hydrophobic adhesive (i.e. Adper Scotchbond Multi-Purpose Adhesive) was always added right after the tested adhesives had been applied according to manufacturers' instructions. All dentin surfaces were checked to ensure complete covering with adhesives before the photo-activation was performed. Adhesives were, then, photo-cured for $10 \mathrm{~s}$ with a light intensity of $500 \mathrm{~mW} /$ $\mathrm{cm}^{2}$ (Degulux Soft-start, DEGUSSA HÜLS).

\section{Fluid Flow Measurement}

An in vitro fluid transport model was used to measure the fluid conductance induced by hydrostatic pressure, following the general guidelines reported by Pashley and Depew ${ }^{19}$ (Figure 1). Each crown-segment was connected via polyethylene tubing to the Flodec device (Flodec System, De Marco Engineering, Geneva, Switzerland) under a constant physiological hydrostatic pressure $\left(20 \mathrm{~cm} \mathrm{H}_{2} \mathrm{O}\right)^{8}$. A pressure gradient between the water reservoir and the specimen induced fluid movement through the specimen. The rate of fluid movement was measured by following the displacement of a tiny air bubble that was introduced into a glass capillary located between the water reservoir and the specimen. Displacement of the air bubble was detected via a laser diode incorporated in the Flodec device. The linear displacement was automatically converted to fluid flow $(\mu \mathrm{L}$ $\min ^{-1}$ ) via the computer software program. The rate fluid flow across dentin was measured two times, sequentially, as follows: 1) after the dentin surface was acid-etched with $35 \%$ phosphoric acid gel (3M ESPE) for $15 \mathrm{~s}$ for the determination of maximum baseline conductance, and 2) after dentin was hybridized following one of the described bonding procedures. All fluid flow measurements were made with the specimen immersed in water to minimize interferences derived from evaporative water fluxes ${ }^{14}$. For each specimen, the fluid flow $\left(\mu \mathrm{L} \cdot \mathrm{min}^{-1}\right)$ across the adhesivebonded dentin was expressed as a percentage of the maximum permeability derived from the acid-etched dentin (assigned as 100\%). This allowed each specimen to serve as its own control, since the same surface area was used in all two measurements ${ }^{6,18}$.

\section{Statistical Analysis}

The percentage fluid flow across the adhesive-bonded dentin for control and experimental groups were analyzed by a two-way ANOVA, having as main factors: the adhesives

TABLE 1- Composition, manufacturers' instructions and batch number of the adhesives used in this study

\begin{tabular}{|c|c|c|c|}
\hline Adhesives & Composition & $\begin{array}{l}\text { Manufacturers' } \\
\text { recommended protocol }\end{array}$ & $\begin{array}{l}\text { Batch } \\
\text { number }\end{array}$ \\
\hline Excite & $\begin{array}{l}\text { HEMA, phosphoric acid, acrylate, } \\
\text { (Bis GMA), dimethacrylate, highly } \\
\text { dispersed silica, catalysts, } \\
\text { stabilizers, ethanol }\end{array}$ & $\begin{array}{l}\text { Apply a generous amount of } \\
\text { Excite. Gently agitate the } \\
\text { adhesive for at least } 10 \mathrm{~s} \text {. Dry } \\
\text { gently for } 1-3 \mathrm{~s} \text {. Cure for } 10 \mathrm{~s} \text {. }\end{array}$ & E30108 \\
\hline Adper Single Bond & $\begin{array}{l}\text { HEMA, BisGMA, dimethacrylate, } \\
\text { copolymer with methacrylic } \\
\text { function, polyacrylic \& } \\
\text { polyitaconic acids, photoinitiators, } \\
\text { water and ethanol }\end{array}$ & $\begin{array}{c}\text { Apply } 2 \text { consecutive coats of } \\
\text { Single Bond, dry gently for } 2-5 \mathrm{~s} \text {. } \\
\text { Cure for } 10 \mathrm{~s} \text {. }\end{array}$ & $3 \mathrm{HW}$ \\
\hline Prime \& Bond NT & $\begin{array}{l}\text { Resin di and tri methacrylate, } \\
\text { amorphous functional silica, } \\
\text { PENTA, } \\
\text { cetylamine hydrofluoride, } \\
\text { photoinitiators, stabilizers, } \\
\text { acetone }\end{array}$ & $\begin{array}{c}\text { Apply } 3 \text { consecutive coats of } \\
\text { Prime \& Bond NT. This surface } \\
\text { should remain fully wet for } 20 \mathrm{~s} \text {. } \\
\text { Gently dry with air for at least } 5 \mathrm{~s} \text {. } \\
\text { Cure adhesive for } 10 \mathrm{~s} .\end{array}$ & 534320 \\
\hline $\begin{array}{l}\text { Adper Scotchbond } \\
\text { Multi Purpose } \\
\text { Adhesive }\end{array}$ & Bis-GMA, HEMA, initiators & $\begin{array}{l}\text { Apply adhesive and light cure for } \\
\qquad 10 \mathrm{~s} \text {. }\end{array}$ & $5 \mathrm{PH}$ \\
\hline
\end{tabular}


TABLE 2- Fluid flow (in percentage) across bonded-dentin when using two-step etch-and-rinse adhesives that were applied as recommended by manufacturers (controls) or coated with an extra coat of the respective two-step etch-and-rinse adhesive or with a more hydrophobic bonding resin

\section{TREATMENTS}

\section{Adhesives}

Manufacturers' recommendation
Extra coat of the respective adhesive
Coat of a

hydrophobic resin

$\begin{array}{lllr}\text { SB } & 38 \pm 14 \mathrm{~A} & 45 \pm 11 \mathrm{~A} & 22 \pm 9 \text { B } \\ \text { EX } & 47 \pm 9 \mathrm{~A} & 41 \pm 15 \mathrm{~A} & 27 \pm 10 \mathrm{~B} \\ \mathrm{~PB} & 39 \pm 13 \mathrm{~A} & 38 \pm 19 \mathrm{~A} & 32 \pm 14 \mathrm{~B}\end{array}$

Values (Mean \pm SD) are expressed as a percentage of the maximum permeability (acid-etched dentin). Groups identified by different letters were statically different $(p<0.05)$.

(i.e. SB, EX and PB) and the experimental dentin treatments (i.e. adhesives application according to manufacturers' instructions, with an extra coat of the respective adhesive or with a coat of a more hydrophobic resin). Post hoc multiple comparisons were performed using Tukey's tests. Statistical significance was preset at $\alpha=0.05$

\section{RESULTS}

Fluid conductance results expressed as percentages of the maximum permeability that occurred in the baseline acidetched dentin are summarized in table 2. None of the adhesives or experimental bonding treatments was able to interrupt completely the transudation of fluid across the adhesive-bonded interface. Reduction in the fluid conductance of acid-etched dentin after adhesives/treatment application was in the range of $53 \%$ to $78 \%$. Regardless of the adhesive system, the application of an extra coat of the respective two-step etch-and-rinse system did not reduce significantly the fluid conductance of dentin when compared to that exhibited by the control groups ( $\mathrm{p}>0.05$ ). Conversely, the application of a relatively more hydrophobic nonsolvated bonding resin reduced significantly the fluid conductance of dentin $(p<0.05)$, irrespectively to the applied adhesive.

\section{DISCUSSION}

The present results indicated the application of an extra coat of the respective two-step adhesive did not reduce the fluid flow across the adhesive-bonded dentin and, thus, did not improve the quality of dentinal sealing. Nevertheless, the simulated conversion of two-step etch-and-rinse adhesives into three-step adhesives, by applying a relatively hydrophobic bonding agent over the primed dentin, significantly reduced the fluid flow across adhesive-bonded interfaces, thereby improving the quality of dentinal sealing. In concert, these results determine the rejection of the first anticipated hypothesis and the acceptance of the second anticipated hypothesis.

Ideally, the dental adhesives should render dentin impermeable, or at least they should reproduce the natural permeability of dentin when this is covered with enamel and/or cementum. However, our results showed that even the most effective treatment used for blocking fluid transudation across the adhesive-bonded dentin (i.e. adhesive + hydrophobic resin) was not able to seal perfectly the dentin. Actually, several previous studies have reported the deficient ability of dental adhesives to keep dentin perfectly sealed $2,6,7$. In addition, some of these studies showed that the smear layer/smear plugs formed in dentin as a result of the operative procedures may be, at short-terms, more effective in sealing the dentinal tubules than the majority of the current dental adhesives ${ }^{3,18,19}$. This suggests that an impervious dentinal sealing may not be easily achieved if bonding procedures are performed after the removal of smear layer/smear plugs by either acid etchants or calcium-chelant agents ${ }^{3,10,29}$. Supposedly, at short-terms, the channels/pathways around the resin tags or the overlying adhesive layer seem to offer less resistance to water movement than do the contiguous channels through the smear plugs/smear layer complex ${ }^{3}$. According to our previous findings, the resin tags seem not to hybridize perfectly with the surrounding water-filled interfibrillar spaces ${ }^{26}$.

Dentinal tubules that become freely unobstructed by the acid etching can readily permit the transudation of dentinal fluid from the pulp toward the surface. Whenever this dentinal fluid transudation occurs, that is, during the infiltration of hydrophilic adhesives ${ }^{11}$ or after adhesive polymerization $^{7,24}$, it may create nanoleakage channels within adhesives ${ }^{25}$ by inducing phase separation of adhesive components ${ }^{23}$, interfering with resin monomers conversion $^{12,23}$ and resin polymers crosslinking, frequently permitting the elution of residual monomers from the polymerized adhesive ${ }^{9}$. Depending on the number and density of these channels and porosities, they may account for a significant increase in the hole-free volume of dental adhesives, which in turn is thought to be intimately related 
with the extent and rate of water diffusion in these polymeric materials ${ }^{15}$. If the dentinal fluid passes through the adhesive, it will accumulate on top of hybrid layer and interfere with coupling to resin composites ${ }^{4,11}$. Nanoleakage channels reported for most of adhesives ${ }^{27,31}$ are, therefore, not only an evidence of material permeability and corrosion, but also a virtual sign of the inability of these adhesives to provide a perfect sealing to dentin.

Deficient sealing of dentin can be also analyzed from the perspective of adhesives polarity ${ }^{7,14}$. The two-step etchand-rinse adhesives used in this study are basically composed of highly hydrophilic monomers (i.e, HEMA, PENTA). Studies on the kinetics of water diffusion have shown a positive correlation between the magnitude of water sorption and the degree of hydrophilicity of experimental adhesives ${ }^{15}$. It is suggested that the absorbed water may form hydrogen bonds with the hydrophilic and ionic domains (i.e. hydroxyl, carboxyl and phosphate groups) present in these hydrophilic adhesives ${ }^{28}$. The water molecules that attach to the polymer chain via hydrogen bonding, referred as "bound" molecules, it is thought to disrupt the interchain hydrogen bonding, induce swelling, and plasticize the polymer ${ }^{1}$. Thus, while it is alarming, it is not surprising to notice that an additional coat of the two-step etch-and-rinse adhesives was not enough to prevent fluid transudation across adhesive-bonded dentin. In fact, in a recent study on the water permeation through multiple layers of organic resin coatings, Nguyen and coworkers ${ }^{16}$ observed that by increasing the number of coats of a hydrophilic resin can only extend the required time for water to permeate completely these coatings, but it did not impede water to move across them.

Clearly, the present results indicated that the permeability of two-step etch-and-rinse dental adhesives can be reduced if they are coated with a resin relatively more hydrophobic. The bonding agent of the Adper Scotchbond Multi-Purpose is based not only on HEMA, but on Bis-GMA (60-70\% $3 \mathrm{M}$ ESPE Technical Profile) and its application over the tested two-step etch-and-rinse adhesives not only increased the time necessary for water to permeate the bonded interfaces, but it may also reduce the percentage of fluid transudation across such interfaces, thereby improving the acid-etched dentin sealing. Undoubtedly, this result corroborates with the notion that three-step etch-and-rinse adhesives, which recommend a separate application of a bonding agent composed of hydrophobic and crosslinking monomers to the primed tooth surface, produce resin-dentin bonds that are more durable than those formed with twostep etch-and-rinse ones ${ }^{29}$. Again, the trend to simplification of adhesives showed to be incompatible with a good dentinal sealing.

Although Bis-GMA forms a polymeric backbone is relatively more hydrophobic, less prone to absorb water than do the highly hydrophilic monomers such as HEMA, PENTA, BPDM, Phenyl-P and others ${ }^{16}$; neither Bis-GMA nor its derivatives co-momonors (i.e. Bis-GMA-E) and other more hydrophobic monomers (i.e.UDMA) used in dentistry exhibit functional groups (i.e. hydroxyls) that are prone to form hydrogen-bond with water molecules ${ }^{22}$, thereby being able to absorb and retain in their resultant polymers a certain amount of water ${ }^{9}$. This could explain why the application of the bonding agent of the Adper Scotchbond Multi-Purpose cannot completely annul the permeability of bonded dentin ${ }^{6,15}$. In fact, the first in vitro study that quantified fluid movement across dentin before and after adhesive bonding showed that the application of Adper Scotchbond MultiPurpose to acid-etched dentin, followed by a 2-mm thick layer of resin composite (Z350, 3M ESPE) did not reduce completely the permeability of dentin, allowing a residual hydraulic conductance of $17 \%{ }^{2}$. Since in the present study we did not apply a resin composite over the bonded dentin, we speculate that the residual fluid movement observed for the groups wherein Adper Scotchbond Multi-Purpose was applied (22-32\%; Table 2) would indirectly correspond to the maximum capacity of this material to reduce the permeability of the acid-etched dentin that has been previously primed with a more hydrophilic, two-step etchand-rinse adhesive system.

Recently, it has been pointed out that the defective dentinal sealing and fluid conductance across resin-bonded dentin may be significantly affected by the solvent used to saturate the acid-etched dentin ${ }^{20}$. The high permeability of dental adhesives bonded to water-saturated dentin (i.e. waterwet bonding technique) probably occur at the expense of a sub-optimal resin infiltration into collagen interfibrillar spaces, both within the intertubular dentin and the circumferential dentin surrounding resin tags ${ }^{3}$. Accordingly, the combined use of water-wet bonding technique and hydrophilic resins compromise the requirements for perfect sealing and durable coupling between resin composites and adhesive-bonded dentin ${ }^{3}$. Thus, the development of a bonding technique that combines the use of hydrophobic resins applied to acid-etched dentin that is saturated with an anhydrous solvent, such as ethanol, could be effective to alleviate the water sorption seen in dentin bonded with hydrophilic simplified adhesives ${ }^{21}$. Application of hydrophobic experimental dental adhesives to ethanolsaturated dentin has shown strong evidences of reduction in bonded dentin permeability and ${ }^{3}$ improvements in the durability of resin-dentin bonds ${ }^{17}$. While it is a promising clinical approach, additional investigations on the performance and technique sensitivity of ethanol-wet bonding technique associated with hydrophobic adhesives are undoubtedly necessary.

\section{ACKNOWLEDGEMENTS}

This manuscript is in partial fulfillment of requirements for the PhD degree for Safira de Marques de Andrade e Silva, Dental School of Piracicaba, University of Campinas, Brazil. This study was supported by grants CNPq (\#474226/ 03-4, 305300/04-0 - P.I. Ricardo Carvalho and \#300615/ 2007-8, 473164/2007-8 - P.I. Marcela Carrilho) FAPESP (\#03/11721-9, 03/04672-1 - P.I. Safira Silva). 


\section{REFERENCES}

1- Adamson MJ. Thermal expansion and swelling of cured epoxy resin used in graphite/epoxy composite materials. J Mater Sci. 1980;15:173645 .

2- Bouillaguet S, Duroux B, Ciucchi B, Sano H. Ability of adhesive systems to seal dentin surfaces: an in vitro study. J Adhes Dent. 2000;2(3):201-8.

3- Carrilho MR, Tay FR, Sword J, Donnelly AM, Agee K, Nishitani Y, et al. Dentin sealing provided by smear layer/smear plugs versus adhesive resins/resin tags. Eur J Oral Sci. 2007;115(4):321-9.

4- Carvalho RM, Pegoraro TA, Tay FR, Pegoraro LF, Silva NR, Pashley $\mathrm{DH}$. Adhesive permeability affects coupling of resin cements that utilize self-etching primers to dentine. J Dent. 2004;32(1):55-65.

5- Cheong C, King NM, Pashley DH, Ferrari M, Toledano M, Tay FR. Incompatibility of self-etch adhesives with chemical/dual-cured composites: two-step vs one-step systems. Oper Dent. 2003;28(6):74755 .

6- Chersoni S, Acquaviva GL, Prati C, Ferrari M, Grandini S, Pashley $\mathrm{DH}$, et al. In vivo fluid movement through dentin adhesives in endodontically treated teeth. J Dent Res. 2005;84(3):223-7.

7- Chersoni S, Suppa P, Grandini S, Goracci C, Monticelli F, Yiu C, et al. In vivo and in vitro permeability of one-step self-etch adhesives. J Dent Res. 2004;83(6):459-64.

8- Ciucchi B, Bouillaguet S, Holz J, Pashley D. Dentinal fluid dynamics in human teeth, in vivo. J Endod. 1995;21(4):191-4

9- Ferracane, JL. Hygroscopic and hydrolytic effects in dental polymer networks. Dent Mater. 2006;22(3):211-22.

10- Hashimoto M, Ito S, Tay FR, Svizero NR, Sano H, Kaga M, et al Fluid movement across the resin-dentin interface during and after bonding. J Dent Res. 2004;83(11):843-8.

11- Itthagarun A, Tay FR. Self-contamination of deep dentin by dentin fluid. Am J Dent. 2000;13(4):195-200.

12- Jacobsen T, Soderholm KJ. Some effects of water on dentin bonding. Dent Mater. 1995;11(2):132-6.

13- Kanca J 3rd. Effect of resin primer solvents and surface wetness on resin composite bond strength to dentin. Am J Dent. 1992;5(4):213-5.

14- King NM, Tay FR, Pashley DH, Hashimoto M, Ito S, Brackett WW, et al. Conversion of one-step to two-step self-etch adhesives for improved efficacy and extended application. Am J Dent. 2005;18(2):126-34.

15- Malacarne J, Carvalho RM, Goes MF, Svizero N, Pashley DH, Tay FR, et al. Water sorption/solubility of dental adhesive resins. Dent Mater. 2006; 22(10):973-80.

16- Nguyen T, Byrd E, Bentz D, Lin CJ. In situ measurement of water at the organic coating/substrate interface. Proc Org Coat. 1996;27:181-93.

17- Nishitani Y, Yoshiyama M, Donnelly AM, Agee KA, Sword J, Tay FR, et al. Effects of resin hydrophilicity on dentin bond strength. J Dent Res. 2006;85(11):1016-21.

18- Pashley DH, Carvalho RM, Pereira JC, Villanueva R, Tay FR. The use of oxalate to reduce dentin permeability under adhesive restorations. Am J Dent. 2001;14(2):89-94.

19- Pashley DH, Depew DD. Effects of the smear layer, Copalite, and oxalate on microleakage. Oper Dent. 1986;11(3):95-102.
20- Pashley DH, Tay FR, Carvalho RM, Rueggeberg FA, Agee KA, Carrilho M, et al. From dry bonding to water-wet bonding to ethanol-wet bonding. A review of the interactions between dentin matrix and solvated resins using a macromodel of the hybrid layer. Am J Dent. 2007; 20(1):720

21- Sadek FT, Pashley DH, Ferrari M, Tay FR. Tubular occlusion optimizes bonding of hydrophobic resins to dentin. J Dent Res. 2007;86(6):524-8.

22- Santerre JP, Shajii L, Leung BW. Relation of dental composite formulations to their degradation and the release of hydrolyzed polymericresin-derived products. Crit Rev Oral Biol Med. 2001;12(2):136-51.

23- Spencer P, Wang Y. Adhesive phase separation at the dentin interface under wet bonding conditions. J Biomed Mater Res. 2002;62(3):447-56.

24- Tay FR, Frakenberger R, Kreijci I, Bouillaguet S, Pashley DH, Carvalho RM, et al. Single-bottle adhesives behave as permeable membranes after polymerization. I. In vivo evidence. J Dent. 2004;32:611-21.

25- Tay FR, Pashley DH. Water treeing-a potential mechanism for degradation of dentin adhesives. Am J Dent. 2003;16(1):6-12.

26- Tay FR, Pashley DH, Kapur RR, Carrilho MR, Hur YB, Garrett LV, et al. Bonding BisGMA to dentin-a proof of concept for hydrophobic dentin bonding. J Dent Res. 2007;86(11):1034-9

27- Tay FR, Suh BI, Pashley DH, Prati C, Chuang SF, Li F. Factors contributing to the incompatibility between simplified-step adhesives and self-cured or dual-cured composites. Part II. Single-bottle, total-etch adhesive. J Adhes Dent. 2003;5(4):91-105.

28- Van Landuyt KL, Snauwaert J, De Munck J, Coutinho E, Poitevin A, Yoshida Y, et al. Origin of interfacial droplets with one-step adhesives. J Dent Res. 2007;86(8):739-44

29- Van Meerbeek B, De Munck J, Yoshida Y, Inoue S, Vargas M, Vijay P, et al. Buonocore memorial lecture. Adhesion to enamel and dentin: current status and future challenges. Oper Dent. 2003;28(3):215-35.

30- Yiu CK, Pashley EL, Hiraishi N, King NM, Goracci C, Ferrari M, et al. Solvent and water retention in dental adhesive blends after evaporation. Biomaterials. 2005;26(34):6863-72.

31- Yoshida E, Uno S, Nodasaka Y, Kaga M, Hirano S. Relationship between water status in dentin and interfacial morphology in all-in-one adhesives. Dent Mater. 2007;23(5):556-60. 